Document downloaded from:

http://hdl.handle.net/10251/180731

This paper must be cited as:

Muñoz Mas, R.; Garófano-Gómez, V.; Andrés Doménech, I.; Corenblit, D.; Egger, G.; Francés, F.; Ferreira, M.... (2017). Exploring the key drivers of riparian woodland successional pathways across three European river reaches. Ecohydrology. 10(8):1-19. https://doi.org/10.1002/eco.1888

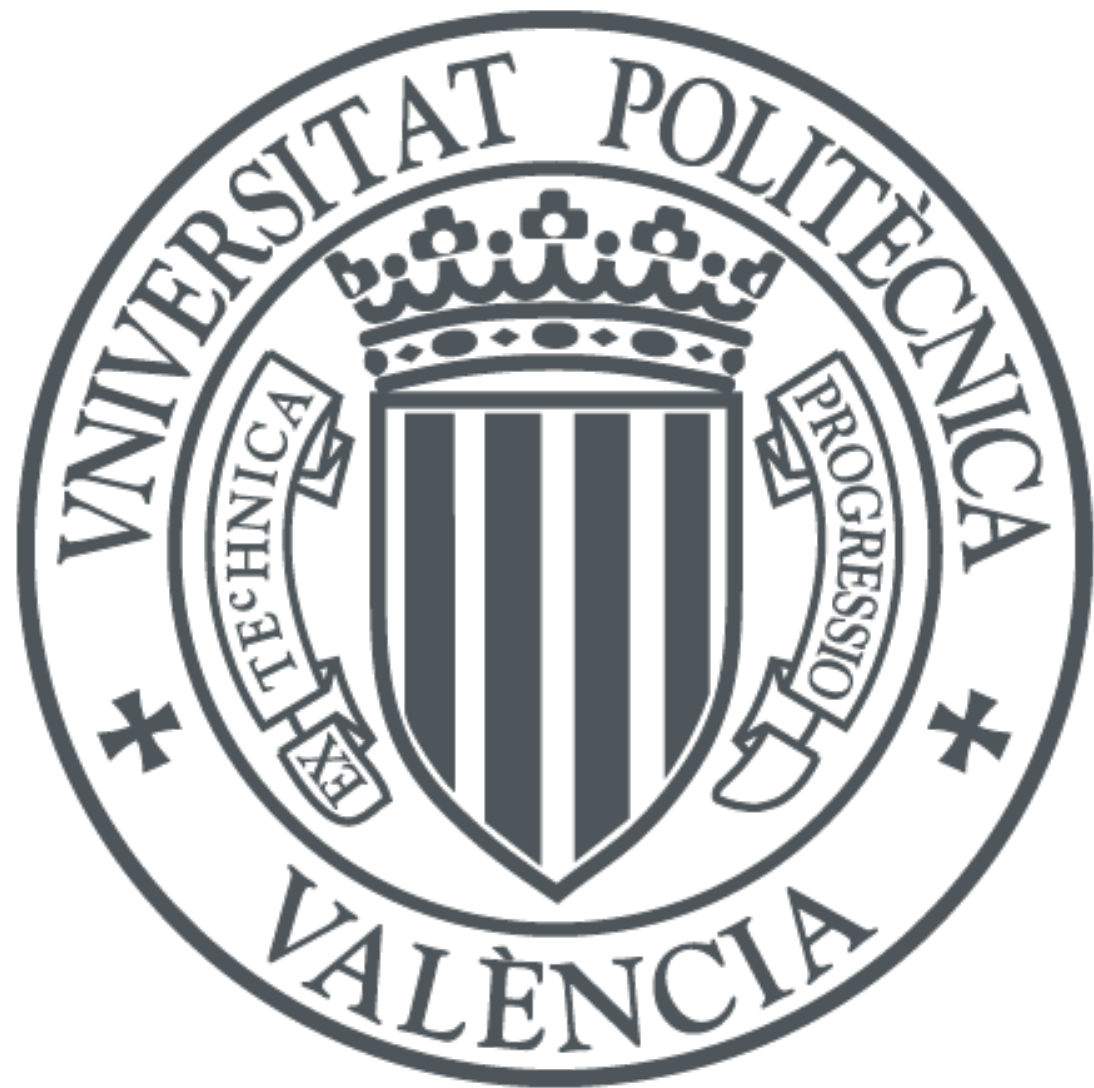

The final publication is available at

https://doi.org/10.1002/eco.1888

Copyright John Wiley \& Sons

Additional Information

"This is the peer reviewed version of the following article: Muñoz-Mas, R., V. GarófanoGómez, I. Andrés-Doménech, D. Corenblit, G. Egger, F. Francés, M.T. Ferreira, et al. 2017. $¿$ Exploring the Key Drivers of Riparian Woodland Successional Pathways across Three European River Reaches.¿ Ecohydrology 10 (8). Wiley: e1888. doi:10.1002/eco.1888, which has been published in final form at https://doi.org/10.1002/eco.1888. This article may be used for non-commercial purposes in accordance with Wiley Terms and Conditions for SelfArchiving." 


\section{EXPLORING THE KEY DRIVERS OF RIPARIAN WOODLAND SUCCESSIONAL PATHWAYS ACROSS THREE EUROPEAN RIVER REACHES}

R. Muñoz-Mas ${ }^{1 *}$, V. Garófano-Gómez ${ }^{1,2}$, I. Andrés-Doménech ${ }^{3}$, D. Corenblit ${ }^{2}$, G. Egger ${ }^{4,5}$, F. Francés $^{3}$, M.T. Ferreira ${ }^{6}$, A. García-Arias ${ }^{3}$, E. Politti ${ }^{5,7}$, R. Rivaes ${ }^{6}$, P.M. Rodríguez-González ${ }^{6}$, J. Steiger $^{2}$, F. J. Vallés-Morán ${ }^{4}$, F. Martínez-Capel ${ }^{1}$

1 Institut d'Investigació per a la Gestió Integrada de Zones Costaneres (IGIC). Universitat Politècnica de València, Paranimf 1, 46730 Grau de Gandia, València, Spain.

2 Université Clermont Auvergne, CNRS, GEOLAB, F-63000 Clermont-Ferrand, France

3 Research Institute of Water and Environmental Engineering, Universitat Politècnica de València, Valencia, Spain

4 Institute of Floodplain Ecology, Karlsruhe Institute of Technology, Josefstrasse 1, D-76437 Rastatt, Germany

5 Environmental Consulting Ltd., Bahnhofstrasse 39, 9020 Klagenfurt, Austria

$6 \quad$ Forest Research Center, Instituto Superior de Agronomia, Universidade de Lisboa, Tapada da Ajuda, 1349-017 Lisboa, Portugal

7 University of Trento, Department of Civil, Environmental and Mechanical Engineering, Via Mesiano 77, 38123 Trento, Italy

*Correspondence to: Rafael Muñoz-Mas. Institut d’Investigació per a la Gestió Integrada de Zones Costaneres (IGIC). Universitat Politècnica de València, Paranimf 1, 46730 Grau de Gandia, València, Spain. e-mail: rafa.m.mas@gmail.com 


\section{ABSTRACT}

Climate change and river regulation are negatively impacting riparian vegetation. To evaluate these impacts, process-based models are preferred over data-driven approaches. However, they require extensive knowledge about ecohydrological processes. To facilitate the implementation of such process-based models, the key drivers of riparian woodland successional pathways across three river reaches, in Austria, Portugal and Spain, were explored employing two complementary approaches. The Principal Components Analyses highlighted the importance of the physical gradients determining the placement of the succession phases within the riparian and floodplain zones. The Generalized Additive Models revealed that the initial and pioneer succession phases, characteristic of the colonization stage, appeared in areas highly morphodynamic, close in height and distance to the water table and with coarse substrate, whereas elder phases within the transitional and mature stages showed incremental differences, occupying less dynamic areas with finer substrate. The Austrian site fitted well the current successional theory (elder phases appearing sequentially further up and distant), but at the Portuguese site the tolerance of the riparian species to drought and flash flood events governed their placement. Finally, at the Spanish site the patchy distribution of the elder phases were the remnants of formative events that re-shaped the river channel. These results highlight the complex relationships between flow regime, channel morphology and riparian vegetation. The use of succession phases, which rely in the sequential evolution of riparian vegetation as a response to different drivers, may be potentially better reproducible, within numerical process-based models, and transferable to other geographical regions.

\section{KEY WORDS}

Fluvial disturbance; generalized additive model; hydrogeomorphological drivers; riparian vegetation; spatially-explicit cross-validation; vegetation succession 


\section{LIST OF ACRONYMS}

CV - Cross-Validation

DE - Differential Evolution

DEM - Digital Elevation Model

EA - Evolutionary Algorithm

FDi - Flood inundation Duration index

GA - Genetic Algorithm

GAM - Generalized Additive Model

GLM - Generalized Linear Model

MDi - Morphodynamic Disturbance index

PC - Principal Component

PCA - Principal Component Analysis

Sn - Sensitivity

Sp - Specificity

TIWI - Time and Intensity Weighted Index

TSS - True Skill Statistic 


\section{INTRODUCTION}

River systems, erstwhile governed by natural flow regimes on the basis of which aquatic and riparian communities have evolved and adapted specifically (Poff et al., 1997), have become broadly flowregulated (Petts and Gurnell, 2005) and morphologically altered (Darby and Simon, 1999) to satisfy human needs such as water supply or irrigation needs (Meybeck, 2004; Habersack et al., 2014). This situation has led to modified flow regimes with increased hydraulic homogeneity, reduced flooding frequencies and increased low water stage during summer (Petts and Gurnell, 2005; Costa et al., 2012). As a consequence, bed morphology has become extensively altered and the reduced connectivity, both longitudinal (main channel and tributaries) and lateral (main channel and floodplain), impaired the vegetation-hydrogeomorphological interactions of natural corridors (Gurnell et al., 2016). These issues are affecting most of the noteworthy river systems of the globe (Nilsson et al., 2005) and, based on the actual trends of the emergent economies (Barletta et al., 2010; Karthe et al., 2014), they will prospectively affect more and more river systems across the planet.

The importance of riparian vegetation stands out over other communities because it usually presents valuable habitat for other organisms such as fish, birds or mammals, which often lead to high biodiversity (Ye et al., 2013). In addition, riparian vegetation provides organic matter to aquatic food webs (Vannote et al., 1980; Baxter et al., 2005). Therefore, decreases in riparian plant biodiversity negatively affects trophic dynamics within river channels (Lecerf et al., 2005). Particularly, the loss of riparian vegetation reduces the quantity and quality of this input into the aquatic food chains (Ström et al., 2012), altering food webs (Wootton et al., 1996), which eventually may lead to novel ecosystems (sensu Morse et al., 2014) or to the ecosystem collapse owing to complex cascading effects (e.g., Jones et al., 1999). 
The sediment and flow regimes play significant roles in the dispersal, recruitment, establishment, growth and succession of plants (Corenblit et al., 2007). Successful riparian plants often adopt a combination of response traits (Violle et al., 2007) during different life stages in order to ensure their survival, such as high dispersal rates, vegetative reproduction or adaptations to resist stressful events (Camporeale et al., 2013; Solari et al., 2016). However, riparian vegetation is not a passive actor but also actively modulates sediment erosion, transport and deposition, exerting a strong control on channel morphodynamics (Corenblit et al., 2007; Gurnell, 2014). Therefore, several riparian plant species were described as ecosystem engineers (Jones et al., 1994) able to alter channel dynamics and habitat conditions through the so-called effect traits (Violle et al., 2007), which characterize the aftermath of the plants on the ecosystem functioning.

To evaluate the threats posed by the human-induced degradation of river systems and accounting for the two-way interaction between vegetation and morphodynamics, the development of scientifically sophisticated numerical models has now become a fundamental area of scientific research (Arthington et al., 2006). Numerical modelling of riparian vegetation is a complex task which typically involves multidisciplinary teams encompassing, among others, biogeomorphologists, hydrologists and data scientists (Cerone and Scotti, 2015). Fated by the complexity of the physical and biological interactions, scientists and engineers have traditionally tackled the problem following divide-and-conquer approaches (Camporeale et al., 2013; Solari et al., 2016). Thus, the vegetation dynamics, sediment transport or bank erosion have typically been modelled, keeping almost constant most of the remaining elements (Solari et al., 2016). Different numerical modelling approaches with fixed river morphologies have arisen in the recent years specifically addressed to model vegetation dynamics under different management or climatic scenarios (e.g., Benjankar et al., 2011; GarcíaArias and Francés, 2016), while those considering simultaneous and interacting changes of vegetation and channel geometry, either based on cellular automata (e.g., Coulthard et al., 2007; Gran et al., 2015) or physics-based (e.g., Bertoldi et al., 2014), are currently rare (Solari et al., 2016). 
A few remarkable approaches include the modelling of sediment transport and deposition in vegetated areas or bank accretion (e.g., van Oorschot et al., 2016), which are still in their infancy as they are not yet completely understood (Solari et al., 2016). Nonetheless, there is still much to be learnt about the interactions between plants and hydrogeomorphology (Gurnell, 2014) and more research is still required to improve modelling of vegetation dynamics within riparian ecosystems.

Process-based quantitative models are important tools for restoration programs because they provide scientific insight to managers and stakeholders in the form of Decision Support Systems (DSSs) (Egger et al., 2012; Benjankar et al., 2014). However, the main difficulty addressing process-based models is the definition of the key physical and biological processes and the subsequent parameterization of these processes, which require a good understanding and monitoring of the studied system and adequately designed in situ and ex situ experiments (Ye et al., 2013). In this regard, statistical or data-driven mathematical models have demonstrated to be supportive tools to overtake the sizable requirements of process-based models (Muñoz-Mas et al., 2016a) and to explore species’ ecological requirements (Muñoz-Mas et al., 2015). In this sense, statistical models have already proficiently complemented field and laboratory experiments (Glenz et al., 2008; Fraaije et al., 2015) as well as process-based vegetation models (Benjankar et al., 2014). For instance, decision trees have been used to predict channel stability (Moret et al., 2006), whereas the superseding random forest technique has been used for species distribution modelling, where its variable importance evaluation method has assisted the exploration of the most relevant ecosystem gradients for wetland vegetation (Peters et al., 2008). Artificial networks have been analogously used to infer the most relevant variables to discriminate riparian from terrestrial forest (Blackard and Dean, 1999), whereas Generalized Linear Models (GLMs) (Nelder and Wedderburn, 1972) have been used to infer the general topographic patterns that determine riparian forest distribution (Shoutis et al., 2010). Finally, fuzzy logic based methods (Zadeh, 1965) have been profusely applied due to their capability to consider expert-knowledge (Muñoz-Mas et al., 2016b). Consequently, fuzzy logic has been used 
to mathematize the stress tolerance of several lowland riparian woody species across Europe, demonstrating their disparate ecological requirements (Glenz et al., 2008).

Process-based approaches have been preferred because statistical models usually rely on the assumption that, both the vegetation and the hydraulic conditions, are in an equilibrium steady state and therefore they may be limited in their application in scenario studies, such as climate change impact assessments (Ye et al., 2013). However, the development and selection of process-based models require extensive knowledge about the underlying processes; the former could be particularly hindered by the difficulty in experimentally describing the real ecosystem precisely and accounting for its complexity (Glenz et al., 2008). In addition, given the temporary extent of some biological and hydrogeomorphological processes - the lifespan of the most prominent western riparian tree species approximates or exceeds one century whereas evolving from a shrub-like to a tree-like life form may last decades (Egger et al., 2015) - experimental studies rarely exceed one single process or phase. For instance, recruitment experiments rarely exceed one lustrum (e.g., Fraaije et al., 2015) and thus, the set and strength of riparian vegetation driving factors for long last processes (e.g., vegetation succession) might be inferred relying on observational data and correlative studies (e.g., Bejarano et al., 2012; Egger et al., 2015; Turner et al., 2004).

Geographic extrapolation of correlative studies is not straightforward because species responses to stressors such as stem flexibility, root length or mechanical resistance to flooding (Glenz et al., 2008; González et al., 2012) may be filtered by environmental features at different spatial and temporal scales (e.g., climate) (Hough-Snee et al., 2015). Nevertheless, different flow regimes have theoretically exerted similar selective pressures on riparian vegetation, resulting in common phenological, morphological, and physiological traits, controlling the spatial and temporal location and appearance of the associations of riparian species (Merritt et al., 2010; Bejarano et al., 2012a; Stromberg and Merritt, 2016). It is possible to integrate this approach by analysing the riparian ecosystem through the concept of succession phases, which take into consideration the colonization 
strategy and development stage of the indicator/dominant species. It does not rely in the specific mixture of species although they share certain traits, but they rather rely in the array of vegetation (i.e., spatial patterns) and its evolution pathway (i.e., temporal patterns) as a response to different physical habitat conditions (Naiman et al., 2005; Egger et al., 2013; García-Arias et al., 2013). Thus, a modelling approach based on succession phases can be potentially transferable to other geographical regions and climates (Egger et al., 2013). Increasing knowledge on succession dynamics, drivers and interactions among them may help the proper implementation and parameterization of dynamic process-based models, which may improve the proper coupling of vegetation dynamics and/or recruitment models with the corresponding hydraulic and hydrologic models. Such dynamic models may help managers to restore the appropriate flow regime and to maintain river functioning, eventually accounting for climate change induced evolutions of the riparian vegetation (Ström et al., 2012; Ye et al., 2013; Benjankar et al., 2014).

In order to improve the knowledge about the key drivers characterizing vegetation succession, the objectives of this study were: i) to analyse the main hydrogeomorphological drivers promoting riparian woodland succession using a comparable approach based on succession phases in three climatically different European river systems; and ii) to distinguish the set of most discriminant hydrogeomorphological drivers that differentiates each phase at each study site. To do so, two complementary approaches were used. First, similarities and differences among the whole set of succession phases was studied employing an unsupervised technique (i.e., Principal Components Analysis - PCA) whereas in the second step a supervised technique (i.e., Generalized Additive Models - GAMs) was employed following a one-versus-all approach to infer the set of variables and non-linear effects that differentiates the target succession phase over the remaining ones. Finally, similarities and differences between the key drivers of the successional pathways of the three study sites are discussed. 


\section{METHODS}

\subsection{Study area}

The vegetation and environmental data were collected during the RIPFLOW project (Francés et al., 2011), which involved three study sites over three different countries (Austria, Portugal and Spain) (Figure 1) encompassing different climates and flow regimes (Peel et al., 2007). Suitable study sites had to present a low or null level of human pressures, a natural state of vegetation dynamics (completely developed sequence of stand ages) and a long-term flow time series from gauging stations nearby the study sites.

[Figure 1 here]

\subsubsection{Drau River (Austria)}

The study site is a 700-m long reach located in the upper course of the Drau River (Austria). Compared to the other two sites, it presents the largest basin area $\left(2555 \mathrm{~km}^{2}\right)$, the highest longitudinal channel gradient (2.2\%), and an intermediate altitude (570 m a.s.l.). Former large braided sections of the Drau River were channelized during the $20^{\text {th }}$ century, but bank revetments were removed between 2001 and 2003 to allow self-forming river processes to occur again. Furthermore, a secondary channel was reconnected to the mainstream to encourage dynamic inchannel erosion and deposition, which eventually triggered the re-naturalization of the site (Formann et al., 2007). The climate is 'humid continental' (type 'Dfb'; snow - fully humid - warm summer) (Peel et al., 2007), which is characterized by long cold winters and mild summers (Figure 2). Although the precipitation is well distributed along the year, the flow regime corresponds to a mixed nival-glacial regime with floods throughout the year, particularly in late spring coinciding with large precipitation events and glacial thaw and snow-melt (Figure 3; upper sequence). This site 
experienced the larger peak flows between 1980 and 1992, although the water yield during vegetative period (April - September) remained barely constant for the entire series (Figure 3; lower sequence).

[Figure 2 here]

\subsubsection{Odelouca River (Portugal)}

The study site is a 398-m long near-natural meandering reach located in the middle course of the Odelouca River. Among the three study sites, it has the smallest basin area $\left(186 \mathrm{~km}^{2}\right)$, longitudinal channel gradient (0.3\%) and mean altitude (132 m a.s.l.). The climate is 'hot-summer Mediterranean' (type 'Csa'; warm temperate - summer dry - hot summer) (Peel et al., 2007), which is characterized by hot and very dry summers and mild and wet winters (Figure 2). It presents a pluvial flow regime, with $80 \%$ of the precipitation usually falling between October and March (Figure 3; upper sequence). During the summer dry season (June-August), the wetted channel becomes typically restricted to a succession of disconnected pools (Boavida et al., 2011). Nevertheless, enormous flash floods can exceptionally occur as a response to sudden and intense rainfall events influenced by the vicinity of the Atlantic Ocean (Figure 3; lower sequence).

[Figure 3 here]

\subsubsection{Mijares River (Spain)}

The study site at the Mijares River is a 539-m long river reach with a short multi-thread channel section located in the upper course of the Mijares River. Among the three study sites, it is the one at 
highest altitude (850 $\mathrm{m}$ a.s.l.), although it has an intermediate basin area (665 km²) and longitudinal channel gradient (0.9\%). The climate is 'cold semi-arid' (type 'BSk'; arid - steppe - cold arid) which is characterized by irregular snowfall, relatively cold winters and hot and dry summers (Figure 2) (Peel et al., 2007). It exhibits a typical Mediterranean-mountainous precipitation pattern, with wet springs and autumns and dry summers, although the river never dries out because it has an important groundwater component. The flow regime is mixed pluvial-nival with two low-flow periods (winter and summer) and two high-flow periods of relatively similar magnitude, one in spring due to precipitation and snowmelt and another during autumn produced by rainfall events (Figure 3; upper sequence), which may provoke high-magnitude flash floods during both periods (Figure 3; lower sequence).

\subsection{Data collection}

Field data were collected between 2008 and 2010 at the three study sites. Although the sites presented different riparian vegetation succession series (woodland, reed or wetland; sensu Kovalchik and Clausnitzer, 2004), we restricted the analyses to the woodland series to obtain the broadest possible picture of the successional process because this series is common to all sites and presents the longest pathway. It starts from bare soil and ends with the oldest individuals (mature mixed forest). The sampling area in each site approximately fitted the area laterally covered by the flood with a recurrence interval of 100 years (Turner et al., 2004). Longitudinally, the length of the site was defined to cover an existing variety of habitats, vegetation types and stand ages characteristic of the surrounding river segment (Fausch et al., 2002). 


\subsubsection{Field vegetation mapping}

Homogeneous vegetation patches larger than $5 \mathrm{~m}^{2}$ were visually delineated on contemporary aerial images to immediately after check and characterize them in the field in terms of species composition (dominant species), physiognomy (percentage of vegetation cover and open soil) and seral stage (tree size class). Thus, the patch became the ultimate riparian vegetation sampling unit (Bagstad et al., 2006; Egger et al., 2012). Stem diameter measurements and tree cores and sections (for large and small individuals, respectively) of the most representative indicator species of the succession phases were sampled to develop growth curves (Stromberg, 1998). These curves allowed the estimation of the patches' age (based on the age of the 3 or 4 largest individuals on each patch). Tree ageing was performed using standard dendrochronological methods (Fritts, 1972). In addition, each patch was also qualitatively characterized in terms of other hydrogeomorphological processes, such as geomorphic disturbance and flood frequency, defined by five classes, from very high to very low (Table 1) (Egger et al., 2015).

The classification of patches into succession phases was made taking into consideration the species composition, age and development stage of the individuals within the patch (Bagstad et al., 2006; Egger et al., 2013) (Table 2). The sketches from the field were converted into polygon shape files using ESRI® ${ }^{\circledR}$ ArcMap $^{\mathrm{TM}}$ v.9.2 (Redlands, CA, USA), their attribute table was completed and finally they were converted into raster grids. The aquatic zone (i.e., the area permanently submerged) of the resultant succession phases’ maps was slightly modified in order to adapt the water surface limits to the different flow regimes of the three study sites: at the Austrian site, water surface limits of the aquatic zone were adjusted to the mean flow conditions; at the Spanish site, they were adapted to the base flow conditions and at the Portuguese site, they were considered as the remaining pools during summer low flows. 
[Table 1 here]

[Table 2 here]

\subsubsection{Physical habitat characterization}

Stand condition is largely characterized by magnitude, frequency, duration, timing, and variability of the flow regime, by local topography (which in turn determines the height above the riverbed), along with local substrate characteristics of the channel and floodplain, which define gradients of water/moisture availability (Naiman et al., 2005). To summarize these elements, seven different variables were considered: distance to thalweg (m), height above reference flow (m), geomorphic disturbance (-), flood frequency (-), substrate index (-) and the Time and Intensity Weighted Indices (TIWIs) of Morphodynamic Disturbance $\left(\mathrm{MDi}-\mathrm{N} / \mathrm{m}^{2}\right.$ ) and Flood inundation Duration (FDi days/year). Flow related variables were determined performing 2D hydraulic modelling and flow time series analyses (see below) while substrate composition was determined in situ.

\subsubsection{Topographic survey and hydraulic modelling}

A topographic survey was carried out in each site encompassing the active channel and the floodplain to develop the Digital Elevation Models (DEMs) necessary to implement the hydraulic models. Specifically, the DEMs were developed based on a Lidar flight at the Austrian site; through GIS processing of the topographic data recorded with a Leica 500 GPS at the Portuguese site; and through a photogrammetric restitution of the images taken with a Cessna T-310-R plane equipped with Ultra CAM-X cameras at the Spanish site. The stability of the main channel was ascertained inspecting the existing former aerial photographs, which were taken in 2005/2007, 1995 and 
1985/2000 for Austria, Portugal and Spain, respectively (García-Arias et al., 2013). The cell size chosen for the three sites for the different GIS raster layers was $1 \mathrm{~m}^{2}$.

In order to characterize the hydrometry of each site, permanent perpendicular transects to the main flow direction were defined in each site. Depth and mean flow velocity were measured at similar spacing segments along each cross section during at least two field campaigns of contrasting flows. This information was later used for the calibration of the hydraulic models (García-Arias et al., 2013; Rivaes et al., 2013).

A 2D hydraulic model was developed in each site combining the DEM, historical flow time series (1980-2009) and the flow-rate curves obtained from the hydrometric surveys and the nearby gauging stations. These models, of similar resolution $\left(\sim 1 \mathrm{~m}^{2}\right)$, were calibrated to minimize the differences between predicted and observed water depths and flow velocities, varying the necessary parameters and bed roughness. In this sense, bed roughness was introduced in the models by a map of polygons (patches) with different Manning's numbers or roughness coefficients, which accounted for the spatial distribution of substrate classes and succession phases. At the Austrian site, hydrodynamics were simulated using the two-dimensional numerical flow model RSim-2D, a part of the RSim river modelling framework (Tritthart and Gutknecht, 2007). At the Portuguese site, hydraulic modelling was performed using the River2D model software (Steffler and Blackburn, 2002). Finally, at the Spanish site, hydraulic simulations were obtained with the Guad-2D software package developed by INCLAM Ltd (Murillo et al., 2008) (see documentation available at http://www.iiama.upv.es/RipFlow/ for further details about hydraulic modelling).

Water table elevation (to determine the height above the reference flow) and shear stress maps for relevant flows, based on the flow duration curves, were obtained for each site. The mean annual flow was considered as the reference flow in the Alpine site $\left(125 \mathrm{~m}^{3} / \mathrm{s}\right)$, while the base flow was the reference flow in the Mediterranean sites (Spain - $0.2 \mathrm{~m}^{3} / \mathrm{s}$ and Portugal - $0 \mathrm{~m}^{3} / \mathrm{s}$ ) because the difference between mean and base flow was considered to be relevant in these two other sites due to 
the presence of an evident dry season. The water surface elevation maps obtained from the hydraulic simulations were interpolated horizontally under the banks with the Thiessen proximity algorithm to obtain a value for the water table elevation all along the floodplain area of each study site (GarcíaArias et al., 2013).

For those attributes with a spatial distribution in the format of raster GIS layers, a resampling systematic technique was undertaken to extract information throughout the study site and to capture their variability. A grid of points $(2 \times 2 \mathrm{~m}$ for the Austrian and Portuguese site and $1 \times 1 \mathrm{~m}$ for the Spanish site) was used to extract information from each patch, specifically from the DEM and the water table elevation map. With the last two maps, the relative elevation of each point above the reference (mean/base) flow was calculated, as well as the horizontal distance from each point to the thalweg.

The current array of riparian vegetation is determined by the counterbalance between the time and intensity of physical disturbance events and the biological communities' resistance and resilience (Pickett and White, 1985). The TIW Is capture this concept in a measurable quantity by considering the magnitude and timing of past flood events, with major and recent events being more heavily weighted than minor and older ones (Egger et al., 2017). The most prominent disturbance factors are probably those deriving from the morphodynamic disturbance and the flood inundation stress (Egger et al., 2013). Therefore, two different TIWIs have been proposed (Egger et al., 2017): MDi (Morphodynamic Disturbance) and FDi (Flood inundation Duration), which are calculated after equations 1 and 2.

$$
\begin{aligned}
& M D i=\frac{\sum_{1}^{T} \frac{\tau}{t}}{\sum_{1}^{T} \frac{1}{t}}(\text { Equation 1) } \\
& F D i=\frac{\sum_{1}^{T} \frac{y_{t}}{t}}{\sum_{1}^{T} \frac{1}{t}}(\text { Equation 2) }
\end{aligned}
$$


where, the numerator of the TIWI of morphodynamic disturbance (i.e., MDi) is calculated by summing the ratio of max. year-round shear stress $\tau_{t}\left(\mathrm{~N} / \mathrm{m}^{2}\right)$ stood at each pixel divided by the corresponding year ordinal number (1980-2009) and the one of flood inundation duration (FDi) by summing the number of days $y_{t}$ (days/year) flooded between April and September, which is likewise divided by the corresponding year ordinal number (1980-2009). That period corresponds to the primary interval of physiological activity of vegetation for temperate ecoregions of the Northern hemisphere (Egger et al., 2017). Then, both sums are divided by the $\mathrm{T}^{\text {th }}$ partial sum of the harmonic series, which is depicted at the denominator of the equations (see the lower sequence of Figure 3 for a complete depiction of the water yield during vegetative period and the maximum annual flow at the three study sites).

\subsubsection{Substrate composition}

Along with the vegetation assessments, the percentages of surface-subsurface coverage (excavating the upper $40 \mathrm{~cm}$ layer) of nine substrate types were visually estimated - bedrock, large boulders (>1024 mm), boulders (256-1024 mm), cobbles $(64-256 \mathrm{~mm})$, gravel $(8-64 \mathrm{~mm})$, fine gravel $(2-8$ $\mathrm{mm})$, sand $(62 \mathrm{~mm}-2 \mathrm{~mm})$ and silt $(<62 \mathrm{~mm})$ - and the presence of organic and litter layer were ascertained.

The substrate composition was converted into a single index by summing the weighted percentages of each substrate type as follows: $0.08 \times$ bedrock $+0.07 \times$ boulder $+0.06 \times$ cobble $+0.05 \times$ gravel $+0.04 \times$ fine gravel $+0.03 \times$ sand (Mouton et al., 2011). Finally, on the basis of the substrate types, the function autoKrige included in the package automap (Hiemstra et al., 2009) of the free software $R$ (R Core Team, 2015) was used to obtain continuous interpolated values of the substrate index across the entire domain of each study site. This package performs an automatic 
interpolation (krigging) minimising the sums of the squared errors through optimal variogram estimation (i.e., optimal model, sill, range and kappa). Violin plots summarizing each dataset can be found in Appendix A.

\subsection{Data analysis}

A two-step exploratory framework was used to scrutinize the relationship between each succession phase present and the seven environmental variables. First, Principal Components Analysis (PCA) (Pearson, 1901) was used to perform an unsupervised analysis to obtain a general picture of the underlying processes, whereas Generalized Additive Models (GAMs) (Hastie and Tibshirani, 1990) were used to infer the most discriminant variables' set per succession phase (i.e., one succession phase vs. the remainder phases) and non-linear effects.

\subsubsection{Principal Components Analysis - PCA}

PCA has been recognized as a useful method to explore riparian vegetation distribution patterns (e.g., Bejarano et al., 2012) because it can be displayed in low-dimensional plots - typically of order two (biplots - Gabriel, 1971) - that summarize the data set variance and the dominant gradients (Paliy and Shankar, 2016). The PCAs were calculated in the free software $R$ (R Core Team, 2015) employing the function principal of the package psych (Revelle, 2015), which relies in a correlation matrix instead of raw data. Consequently, nor previous standardization neither normalization was performed. Highly correlated variables may be less informative because they load on the same Principal Component (PC) and artificially increase the variance explained by the corresponding PC (Quinn and Keough, 2002; Zuur et al., 2007). Therefore, to increase the interpretability of the biplots, a conservative value $\left(r^{2}<0.66\right)$ was employed to select the set of uncorrelated variables that maximized the explained variance in only two PCs (e.g., Paz-Kagan et al., 2016). Correlation values 
and matrices were calculated employing the function hetcor in the package polycor (Fox, 2010) because the original dataset included continuous and discrete variables.

\subsubsection{Generalized Additive Models - GAMs}

GAMs are a semi-parametric extension of general linear models especially indicated for ecological modelling and thus, they have been applied in a number of ecological studies (e.g., Muñoz-Mas et al., 2016b; Ye et al., 2013). The main advantage of GAMs relies on their flexibility because the form of the functions modelling the effect of the input variables over the response variable is unspecific (i.e., the $s$ in equation 3) (Ye et al., 2013). As a consequence, GAMs fit well the ecological gradient theory, which states that the ecological predictors affecting living organisms can be formalised by employing monotonic or unimodal (intermediate optimum) functions (Austin, 2007). That versatility is an advantage compared to other classical approaches such as logistic regression (Cox, 1958) or Generalized Linear Models (GLMs) (Nelder and Wedderburn, 1972), that constraint variables' effects to linear or monotonic responses compelling the optima to either extremes to the range. The general formula corresponds to:

$$
\mathrm{G}(\mathrm{E}(\mathrm{y}))=\beta_{0}+\sum_{\mathrm{i}=1}^{\mathrm{n}} \mathrm{s}_{\mathrm{i}}\left(\mathrm{x}_{\mathrm{i}}\right)(\text { Equation 3) }
$$

where $y$ is the response variable to be predicted, $E(y)$ is the expected value of $y, x_{i}$ is a set of $n$ predictor variables, $G()$ is the link function, which relates the linear predictor on the right-hand side to $E(y)$, and $s_{i}$ are non-parametric smooth functions, which are typically third degree smooth splines (Ye et al., 2013).

The GAMs were developed in $R$ (R Core Team, 2015) with the package $m g c v$ (Wood, 2004). A oneversus-all approach was followed. Therefore, before training each of the GAMs, the data on the 
target phase were converted to a one (present) and the remaining phases to a 0 (absent). In accordance, the link function (i.e., the $G$ in equation 3) was set to binominal (logit link).

Three major interrelated features requiring optimisation control GAMs performance: the number of selected inputs, over-parameterization (i.e., the excessive number of effective degrees of freedom) (Alcaraz-Hernández et al., 2016) and data prevalence (i.e., the ratio of presence data within the entire dataset) (Platts et al., 2008). Therefore, a wrapper approach (see e.g., Muñoz-Mas et al., 2016), based on Cross-Validation (CV) and Genetic and Evolutionary Algorithms (GA \& EA) (Holland, 1992), was used to obtain the most relevant non-correlated $\left(r^{2}>0.66 ; p\right.$-value $\left.\leq 0.1\right)$ input variables (Peters et al., 2008), the optimal number of effective degrees of freedom (Arlot and Celisse, 2010), and the case weights (in order to balance the error committed on presence and absence data) (Muñoz-Mas et al., 2016a).

\subsubsection{Spatially-explicit cross-validation - CV}

Data on succession phases was collected encompassing uniform patches (one single succession phase appeared in each patch), although the exploratory analysis, either supervised or unsupervised, followed a pixel-based scheme. Depending on the country, the sampling size for each phase differed substantially from hundreds to thousands of pixels. As a random division of the data set to perform the validation may have implied problems of pseudo-replication (violation of independence) (Hurlbert, 1984), we decided to optimise the data partition employing the Differential Evolution (DE) algorithm (Storn and Price, 1997). This ensured the presence and balanced proportion of all the succession phases in each one of the folds (i.e., spatially explicit disjoint parts of the sites).

The 2D coordinates of three centroids (X, Y) were optimised at each site and each sample (i.e., pixel) was assigned to the nearest one (Euclidean distance). The fitness function consisted of the mean value of the different phase proportions between the three folds (i.e., 1 - mean value), although if a 
given class was not present in any of the optimised subsets the function rendered an unfeasible solution. The implementation of the DE algorithm was the one in the $R$ package DEoptim (Mullen et al., 2011), whereas the parameters settings of the optimisation were based on the recommendations described in Mullen et al. (2011) and the package’s vignette (Table 3).

[Table 3 here]

\subsubsection{GAMs optimisation}

The optimisation of the GAM, consisting in the selection of the best input variables subset, the max. effective degrees of freedom or max. number of knots (i.e., the number of nick points of every smooth curve) allowed per spline and the case weights was performed simultaneously with genoud, the GA comprised in the R package Rgenoud (Mebane Jr and Sekhon, 2011). The potential solutions were sequences of integers; the first part corresponded to the GAM's parameters (restricting the search between 0 and 4 for the max. number of knots and from 1 to 99 for case weights), and the rest to the seven input variables (see Muñoz-Mas et al., 2016 for futher detail of the wrapper approach). Although genoud presents 9 different operators driving the optimisation (Mebane Jr and Sekhon, 2011) we constrained the algorithms to make use only of three of them, thus genoud performed analogously to classical GAs (Table 3). The population size and the number of generations were set at 100 and the optimisation halted after 25 generations without improvement. The objective function corresponded to the maximisation of the True Skill Statistic (TSS $=S n+S p-1$ ), weighted by the number of cases encompassed in the validation dataset. Sensitivity (Sn) corresponds to the ratio of presence data classified as presence whereas Specificity $(S p)$ to the ratio of absence data classified as absence (see Mouton et al., 2010 for additional information on performance criteria). 
Following previous studies (Fukuda et al., 2013; Muñoz-Mas et al., 2016), once the optimal parameters and variables were obtained, a single GAM was calculated for further inspection and the relationship between the input variables and the probability of presence was graphically visualized with univariate partial dependence plots (Friedman, 2001).

\section{$3 \quad$ RESULTS}

\subsection{General successional pathway influenced by flow regime and local factors: unsupervised exploratory analysis - PCA}

The study site located at the Drau River (Austria) presented four different phases of the woodland series. The first and second PCs summarized respectively the $35.5 \%$ and $25.3 \%$ of the variance (Figure 4 left). The first PC characterized site geometry, thus it was mainly correlated with height above mean flow and to a lesser extent with geomorphic disturbance. The second PC combined the timing and intensity of disturbance events and the sedimentology of the site therefore; it was correlated with MDi (Morphodynamic Disturbance) and substrate index. The remaining variables (i.e., distance to thalweg and flood frequency) loaded equally on either PCs.

The succession phases segregated mainly along the first PC (site geometry); with elder phases occurring at higher areas above mean flow (Figure 4 right). In addition, the succession phases were positioned on a gradient defined by the variables geomorphic disturbance and flood frequency, associating low values of these variables to younger phases and higher to the elder ones. The shrub phase occurrence was also markedly conditioned by the second PC, as this phase occurred in currently inactive areas (low MDi) of finer substrate.

[Figure 4 here] 
The study site located at the Odelouca River (Portugal) presented five succession phases. The first and second PCs summarized $44.7 \%$ and $17.3 \%$ of the variance, respectively (Figure 5 left). The first PC was positively correlated with flood frequency, height above base flow and distance to thalweg and negatively with substrate index and FDi (Flood inundation Duration). Thus, it characterized physiological stress due continued water scarcity. The second PC was exclusively related with MDi characterizing the time and strength of the past peak flows (disturbance intensity).

The ordiplot (Figure 5 right) depicted great overlapping between succession phases. Nevertheless, the initial and pioneer phases, and to a lesser extent, the early successional phase occurred in areas of coarse substrate recently and recursively flooded (i.e., with high values of substrate index and FDi). Conversely, the established and mature forest phases occurred in high and distant areas to the thalweg and consequently rarely flooded (high values of flood frequency). The second PC showed that the younger phases, like initial and pioneer, presented higher values and variability of MDi than the older phases; being especially remarkable the case of the mature forest phase, which occurred in areas that did not experience recent and/or high shear stresses.

[Figure 5 here]

The study site at the Mijares River (Spain) presented the largest number of succession phases (i.e., seven). The first and second PCs summarized 35.9\% and 17.5\% of the variance, respectively (Figure 6 left). On the one hand, the first PC was positively correlated with height above base flow, flood frequency and distance to thalweg whereas, on the other hand, it was negatively correlated with the MDi and FDi indices. Therefore, this PC encompassed the geomorphodynamism of the site. The second PC was exclusively correlated with substrate index. 
The ordiplot displayed enormous overlapping between most of the succession phases without clear segregation along any of the PCs (Figure 6 right). Nevertheless, the pioneer and, to a lesser extent, the initial phases occurred in areas of coarse substrate that steadily stand high values of shear stress (i.e., high $\mathrm{MDi}$ ).

[Figure 6 here]

\subsection{Key hydrogeomorphological drivers of each successional phase: supervised exploratory analysis - GAMs}

\subsubsection{Array of succession phases and data partition: spatially explicit Cross-Validation (CV)}

The patches of the woodland series at the Drau River (Austria) appeared principally encompassing a nugget-like shape close to the secondary channel apart from the initial phase, which appeared bordering the nugget and scattered along the shores (Figure 7). In accordance, the DE algorithm divided the site in three pie-like pieces with a good balance between proportions except for the pioneer phase, which was almost absent in one of the partitions (Table 4).

At the Odelouca River (Portugal) the succession phases presented notable topographic segregation with the initial phase principally on the centre of the channel and the elder phases segregated towards higher elevated floodplain areas (Figure 7). The pioneer phase appeared in two dissimilar locations. The first one was over one bank whereas the other was inserted within the central patch of the initial phase. The site was also divided in three pie-like pieces with a good balance of proportions (Table 4).

The Mijares River (Spain) presented the narrowest segment with the largest patchiness and heterogeneity (Figure 7). Succession phases alternated within site belts and thus, the DE algorithm 
transversally divided the site in three folds with a good balance between proportions, although the herb phase presented few data in Fold 1 (Table 4).

[Figure 7 here]

[Table 4 here]

\subsubsection{Key drivers of successional phases: genetically optimised GAMs}

\subsubsection{Performance}

The performance criteria varied between sites and succession phases. However, they were generally high, particularly for the colonization stage, because the True Skill Statistic ( $\overline{\mathrm{TSS}}$ ) obtained during the 3 -fold CV was in most of the cases above 0.5 , which corresponded to a mean accuracy of $75 \%$ (Table 5). In some cases, this value decreased below this threshold (e.g., for the early successional phase at Portugal), although the high sensitivity $(\overline{\mathrm{Sn}})$, which corresponds to the ratio of presence data classified as presence, compensated these decreases.

[Table 5 here]

\subsubsection{Selected variables and variables’ effects}

At the Austrian site, the presence of initial phase was determined by low height above mean flow, coarse substrate and large distance to the thalweg because these distant patches were close to the secondary channel (Figure 8). Pioneer phase presence was related to high geomorphic disturbance and low height above mean flow, although this phase avoided the lowest sites, which were occupied 
by the initial phase. Pioneer phase also occurred distant to the thalweg, although, compared with the initial phase; it appeared in the inner side. Pioneer shrub phase occurred behind the initial phase thus its probability of presence was higher in areas of intermediate height above mean flow. Finally, the shrub phase occurred in areas currently inactive therefore, the probability of presence was higher in areas of low FDi and MDi.

[Figure 8 here]

At the Portuguese site, the presence of the initial phase was related to low height above base flow, but rarely flooded during recent times (i.e., low FDi), and the presence of gravel substrate (substrate index $~ 5$ ) (Figure 9). Compared to the initial phase, the pioneer phase appeared even closer to the thalweg and the base flow (maxima at zero height above base flow), although these patches experience moderate-to-high geomorphic disturbance. Early successional phase appeared in two longitudinal belts that, depending on the side of the channel bend, presented contradicting optima. Nevertheless, the largest probability of presence occurred for very low flood frequency (score $5=30$ $\leq \#$ years). Established forest phase was present in areas with high-to-moderate flood frequency, far from base flow and fine substrate, but that recently stood high shear stress (i.e., high MDi) because the north-western part of the site is profusely flooded during high flows, which determined the pattern depicted in the partial dependence plot. Finally, mature forest was located in areas far from the active channel of null MDi whereas the underlying substrate was heterogeneous, resulting in a mean value between gravel and cobble (substrate index $~ 5.5$ ). Nevertheless, this succession phase was only marginally present in the studied part of the river.

[Figure 9 here] 
At the Spanish site, the initial phase was present at intermediate distances to the thalweg but suffering, during recent times, more than 50 days of flooding per year (FDi) (Figure 10). It also endured high geomorphic disturbance resulting in coarse substrate (substrate index $~ 6$ ). The pioneer phase presented low sample size $(\mathrm{N}=55)$ thus it was simply characterized by low height above base flow (maximum near zero) and coarse substrate (substrate index $~ 6$ ). Herb phase was distant to the thalweg, although given the multi-thread nature of this river segment, this phase occurred differentially in low areas near the base flow and prone to flooding, which manifested in the very high flood frequency index. However, in that time, this phase did not stand peak shear stresses resulting in a low optimum for MDi. Shrub phase appeared scattered all along the study site enduring disparate hydrogeomorphological conditions and it was exclusively characterized by a high-to-mid flood frequency. Early successional phase probability of presence was higher in spots near the thalweg of high flood frequency index. However, this phase had not stood either recent outstanding flows or recent sustained floods resulting in low optimal values for FDi and MDi. Established forest occurred in areas with moderate geomorphic disturbance, which recently stood large shear stresses. Finally, mature forest was mainly present in areas with moderate geomorphic disturbance. However, this phase appeared relatively close to the thalweg, which evidenced the topographic complexity of this water course.

[Figure 10 here]

\section{DISCUSSION}

We successfully followed an approach similar to previous studies (Turner et al., 2004; De Jager et al., 2012) yet more sophisticated, mainly regarding the application of Genetic and Evolutionary 
Algorithms (GA \& EA) to infer ecological gradients and the most relevant hydrogeomorphological drivers for the different riparian woodland succession phases. Furthermore, we compared three river sites with different flow regimes, one of them ephemeral, which has been alleged to be of special interest due to the relative scarcity of studies on rivers with such kind of flow regimes (Stella et al., 2012).

\subsection{General successional pathway influenced by flow regime and local factors}

The PCAs (unsupervised approach) succeeded in demonstrating the contrasting river geometries and flow regimes across study sites. Therefore, geomorphic disturbance segregated well the succession phases at the Drau River (Austria), which is a phenomena typically observed in rivers without dramatic episodes of water scarcity, in contrast with those observed at the Odelouca River (Portugal) (Turner et al., 2004; Bejarano et al., 2011; Ström et al., 2012). Nonetheless, previous experiences suggested a minor relevance of distance to thalweg due to the presence of backwaters and sloughs or temporary side channels, which produced local wet conditions relatively far from the main channel (Turner et al., 2004; Garófano-Gómez et al., 2009), which fits well with the presence of the secondary channel. The only discrepant phase was the shrub phase, which was also segregated along the second PC (MDi and substrate index) and by distance to thalweg, who loaded equally on both PCs. This pattern may probably be reflecting the feedback between continued stability, which allow vegetation progression, and bank accretion episodes (Gurnell et al., 2016; Solari et al., 2016) because shrubs with multi-stemmed habits, typical from Salicaceae species (Barsoum, 2001), have been remarkably acknowledged to be efficient traps of fine sediment (Corenblit et al., 2009).

The first PC of the Odelouca River was correlated with the whole set of variables but MDi, which correlated with the second PC. The succession phases segregated almost exclusively along the first PC therefore, based on previous correlative and manipulative experiences (e.g., Fraaije et al., 2015; 
Glenz et al., 2008), it highlights the effect of water scarcity and the ability of the species to reach the necessary resources. Riparian vegetation root growth is generally fast and is determined by water availability (Camporeale et al., 2013). Therefore, it has been demonstrated that under waning resources, riparian vegetation tend to recursively colonize areas towards the river thalweg (GarófanoGómez et al., 2013) whereas, once the water scarcity exceeds certain values (i.e., physiological thresholds), it may finally lead to vegetation senescence (De Jager et al., 2012; González et al., 2012). In accordance, the elder phases of this site should have access to deeper layers and may have exerted great effort fixing and accreting the river banks (Gurnell, 2014). There is evidence that bank stability is the main cause of single-channel development and that vegetation development can be sufficient to induce this response (Murray and Paola, 2003; Coulthard et al., 2007). Consequently, those elder phases eventually governed channel pathway causing the ultimate array of succession phases and channel geometry through the acknowledged interactions and feedbacks driving the riparian bio-morphologic environment (Camporeale et al., 2013; Gurnell, 2014).

Unlike the other two sites, the first PC for the Mijares River (Spain) was also correlated with MDi, which segregated the colonization stage (i.e., initial and pioneer phases). The greatest overlapping between succession phases highlighted the usefulness of both complementary approaches (i.e., PCA and GAMs) to unveil the key drivers of riparian succession. However, this site presented the largest complexity, which suggested that neither the flow regime nor riparian vegetation fully govern local bio-morphology. This river segment presents the narrowest riparian zone with steep river banks and rocky outcrops and cliffs that recursively favour large rockslides, a phenomena that has demonstrated to be the main geomorphological driver in some river typologies (Korup, 2005). In this regard, rockslides may be playing a role similar to large woody debris, which may occasionally determine a number of geomorphological changes (Politti et al., 2014). They alter the flow field, influencing bank erosion rates, channel width and depth (Camporeale et al., 2013), and eventually creating new habitats for pioneer plants (Stella et al., 2012). However, owing to its stochastic nature, although 
there have been attempts to involve debris simulation, it demonstrated to be an enormous complex and unsolved task (Camporeale et al., 2013).

\subsection{Key hydrogeomorphological drivers of each successional phase}

\subsubsection{Colonization stage}

Flow regime is the principal driving force for the initial phase because high flows provoke local erosional and depositional areas within the channel and the extent of these areas largely depends on the intensity of these events (Benjankar et al., 2014; Egger et al., 2015). Once these new habitats have been created, the hydrological gradient acts as a strong environmental filter for colonization, through recurrently imposing an abiotic limitation (water excess) at lower elevations, which is the case of the Austrian and the Spanish sites that have experienced recent and continued floods (high FDi) (Fraaije et al., 2015). On the contrary, resource limitation (water shortage) at higher elevations can also regularly occur, which represents a biotic limitation (Fraaije et al., 2015). This is the case of the initial phase at the Portuguese site, which had not recently stood sustained floods (low FDi) (Bagstad et al., 2006). Conversely, other variables, such as soil or organic matter, may only affect recruitment marginally (Turner et al., 2004; Fraaije et al., 2015). At the Austrian site, the optimal GAM suggested a positive relationship between distance to thalweg and initial phase because some patches were close to the secondary channel and thus it should be not viewed as incongruent with the successional theory while, at the Spanish site, geomorphic disturbance suggested yearly sedimentary activity. Due to the multi-thread nature of the site some of the small channels can be dry part of the year, being the reason of some initial phase patches far from the main river thalweg. In this site, the initial phase appeared flanked in corridors by elder phases (principally early successional and established forest phases), which given their flow resistance funnel water through these corridors causing the distribution of the initial phase and the multi-thread channel (Gurnell, 2014). These fringing shrub stands may be derived from pioneering communities on new gravel bars near the 
active channels (Mouw et al., 2013). Nonetheless, these formations could be the remnants of the former vegetation present in the study site prior to the formative flow occurred in 1968 (ca. $650 \mathrm{~m}^{3} / \mathrm{s}$ ) (García-Arias et al., 2013).

Although, desiccation poses a major limitation on plant establishment in Mediterranean river systems (Stella et al., 2012), which is not the case of the Austrian site, the pioneer phase appeared close to the water table (zero height above base flow) in the three study sites. This reflects the fine line between water balance and disturbance governing plant establishment (Fraaije et al., 2015), which is particularly evident for the Portuguese case. Moreover, although the Austrian site coincided in the optimum geomorphic disturbance, the pioneer phase appeared in the lee side of some shrub clumps. The climatic patterns of the Austrian site are more benign for seedlings establishment; however, based on evidence (Geerling et al., 2006), this site should be more dynamic and the limiting factor may be the occurrence of large floods able to uproot these immature plants (Camporeale et al., 2013). In this context, the most suitable habitats are typically in the lee side of existing woody vegetation patches because that areas have been noted to provide shelter and to facilitate sedimentation (Corenblit et al., 2016), which eventually favour moisture retention and plant development (Bejarano et al., 2012a).

\subsubsection{Transitional stages}

The pattern of the transitional stages fitted well with previous studies in temperate rivers, where elevation above thalweg increased significantly from young to old patches, as did distance from the channel and groundwater depth (Turner et al., 2004; Bagstad et al., 2006). However, such a general pattern was described by different variables for each site and succession phase.

At the Austrian site, succession phases were positioned along a clear gradient of elevation linked to bank accretion (Camporeale et al., 2013; Gurnell, 2014). The shrub phase appeared at higher 
elevations than the pioneer shrub phase, and furthermore, in areas rarely flooded that had not experienced recent peak shear stresses.

In Portugal, although the established forest recently stood high shear stress (i.e., high MDi) because the north-western part of the site was profusely flooded during former high flows, it fitted well the expected distribution pattern (i.e., high elevation above base flow, intermediate values of flood frequency and sandy substrate). Conversely, the early successional phase did not present sound preferences. It occurred in contrasting areas, either frequently or rarely flooded, thus being a moderate-to-low flood frequency its only remarkable driver. Nevertheless, these distribution patterns may not be surprising because Salix spp. and Fraxinus angustifolia (both present in different proportions in early and established succession phases) have demonstrated the capability to succeed in fluvial-disturbed areas due to their proficient mechanical properties (Karrenberg et al., 2002), behaving as pioneer species, whereas $F$. angustifolia proved able to persist on more distant and higher sites with other non-obligate phreatophytes because of their ecophysiological competence (high water use efficiency) (Manzanera \& Chacón, 2007).

The transitional stages present at the Mijares River started with the herb phase, which presented characteristics between the colonization and transitional stages. Thereby, it occurred in areas prone to flooding near the base flow but far from the main channel. Consequently, these areas did not recently suffered peak shear stresses, which allowed vegetation progression (Gurnell et al., 2016; Solari et al., 2016). The shrub phase did not show a clear pattern, being present in areas with a wide range of flood frequencies. We consider that this may be caused by the former peak flows and the aforementioned site stochasticity with its frequent rockslides combined with the capability of Salix spp. and Populus spp. to reproduce asexually, and therefore resprout vigorously from buried fragments in less exigent conditions than seedlings in pioneer patches (Barsoum, 2001; Karrenberg et al., 2002). The locations occupied by the early successional phase were characterized by recent and sustained floods and peak shear stresses (i.e., high MDi), which emphasizes the adaptability of 
riparian vegetation to unsuitable and disrupting conditions (Murray and Paola, 2003; Coulthard et al., 2007; De Jager et al., 2012). The oldest phase of this stage (i.e., established forest phase), incrementally occurred at lower flood frequency and occupied sites of minor geomorphic activity, which fits well the general gradients described for succession phases (Ström et al., 2012; Camporeale et al., 2013; Gurnell, 2014).

\subsubsection{Mature stage}

Mature stages occupy the areas located at the limits of the riparian zones and are more likely prone to human intervention (Turner et al., 2004; Méndez-Toribio et al., 2014). Mature stage was not present in the area studied in the Austrian river site and it was poorly represented at the Portuguese site (Rivaes et al., 2013). In the Odelouca River, it was located in the inactive part of river banks (null MDi), most probably constrained by the surrounding landscape dryness, and naturally occupying only small patches incrusted on the terrestrial vegetation. On the contrary, the mature forest present at the Mijares River appeared in areas with intermediate geomorphic disturbance (rarely flooded) but relatively close to the thalweg, which highlights the capability of riparian vegetation to stabilize and thrive on active river banks (Murray and Paola, 2003; Coulthard et al., 2007).

\subsection{General prospect, further considerations and conclusions}

Vegetation succession phases could be described for all sites and coherently articulated in their relationships with river dynamics. The differences detected between phases highlight the complex relationship between flow regime, channel morphology and riparian vegetation (Camporeale et al., 2013; Gurnell, 2014; Solari et al., 2016). Nevertheless, the similarities among the three sites, (i.e., colonization stage occurred close to the reference flow while mature stage occurred principally in stable spots) proved the usefulness of succession phases on a very wide cross-regional context where 
species-based analyses could be hardly performed (Merritt et al., 2010). Particularly, when comparing Alpine and Mediterranean vegetation because species-specific traits may exert control over its competitive and/or facilitative abilities (Bagstad et al., 2006; Bejarano et al., 2012). The use of succession phases, which rely in the sequential spatial array of vegetation and its temporal evolution as a response to different drivers has proven to be transferable between geographical regions and therefore, may be better reproducible within numerical process-based models (e.g., García-Arias and Francés, 2016).

Interestingly, MDi was underrepresented in the supervised analysis (i.e., GAMs) despite it was considered the main driver in previous studies employing the current data (García-Arias et al., 2013). This mismatch between preconceived main drivers and those eventually observed were already pointed out (Rivaes et al., 2014). Thus, our results combined with these prior concerns highlight the enormous complexity faced by scientists and modellers to tackle riparian vegetation dynamics (and hence bio-hydrogeomorphology) encompassing its entire spatial-temporal dimension (Camporeale et al., 2013; Solari et al., 2016), especially when no clear patterns can be observed in the study sites (e.g., Van Looy et al., 2006; Mouw et al., 2013). Furthermore, land-cover history, which has not often been considered in studies of floodplain vegetation, can play an essential role in explaining vegetation successional stages as it can introduce additional heterogeneity in riparian vegetation that is not directly related to hydrogeomorphological variables such as elevation or distance from the river (Turner et al., 2004; Méndez-Toribio et al., 2014). Currently, very few areas across the globe can be considered pristine (Meybeck, 2004), so we cannot discard that some of the observed incongruences with the main succession pathway theory (Camporeale et al., 2013; Gurnell, 2014) would not be caused by former human interferences.

Although the scope of riparian studies should be enlarged beyond the reach scale in order to avoid the oversimplification of the spatial variability in environmental drivers (Stella et al., 2012), this study rendered important hints to sound ecological management in the spatial-temporal context on 
which the riparian landscape has to be viewed (Carbonneau et al., 2012). Despite recent and successful attempts (van Oorschot et al., 2016), it is clear that a single overall strategy for numerical process-based implementation and consequently, for biodiversity conservation of riparian vegetation is difficult. Therefore, strategies should be derived for separate river reaches based on specific characteristics of the reach and the influence of the surrounding ecoregion (Van Looy et al., 2006).

The Austrian site did not suffer the effect of water shortage therefore its modelling could proficiently be addressed employing currently classical approaches that neglect water availability in none-wetted areas (e.g., Egger et al., 2012; García-Arias et al., 2013). Nevertheless, novel numerical process based approaches, especially indicated to meandering river segments, will be most likely able to render paramount results (van Oorschot et al., 2016). Conversely, the Portuguese and, to a lesser extent, the Spanish sites should be addressed with schemes taking into account groundwater levels and soil moisture. In this regards, frameworks accounting for groundwater availability (e.g., Bertoldi et al., 2014) or novel numerical process-based models as the RVDM (García-Arias and Francés, 2016) may be better suited to undertake them. However, model accuracy on narrow sites with complex vegetation arrays, multi-channel sections and the introduction of exotic material may be hardly improved despite the good performance achieved by former studies on the site (García-Arias et al., 2013; García-Arias and Francés, 2016). Thus, more complex approaches accounting for sedimentological and braided channel morphodynamics (e.g., Gran et al., 2015; van Oorschot et al., 2016) may not worth the enormous effort necessary to gather the necessary information. Nonetheless, the acknowledge influence of exogenous material, which may imply sudden morphological changes, or the spatial scale of channel morphodynamics, which could be of similar magnitude than the error in some numerical process-based models (e.g., Gran et al., 2015; van Oorschot et al., 2016), could currently dissuade modellers of making use of them.

The results from this study are necessary to cope with the recent research needs associated with the new field of biogeomorphic interactions. In addition, we have made an original contribution of detail 
observational data from across different biogeographic regions, out of the temperate region, where the vast majority of the models have been developed until now (Stella et al., 2012). This study showed similarities but also remarkable differences at the functional level, and rendered valuable insights about the main drivers governing the successional pathways of riparian vegetation of three contrasting flow regimes across Europe. Knowing the drivers affecting successional phases can contribute to projects that attempt to restore the ecological quality of rivers, such as factually enlarging the width of channelized rivers, in several parts of the world. Furthermore, this knowledge should assist the adequate selection of the modelling approach and may favour the use of succession phases in further developments of numerical process-based models for the simulation of riparian vegetation.

\section{CONFLICT OF INTERESTS}

None of the authors has any conflict of interests related with the content of the article.

\section{ACKNOWLEDGMENTS}

This work was supported by the IWRM Era-NET Funding Initiative through the RIPFLOW project (references ERACCT-2005-026025， ERA-IWRM/0001/2008， CGL2008-03076-E/BTE), http://www.old.iwrm-net.eu/spip.php, by the Spanish Ministry of Economy and Competitiveness through the project SCARCE (Consolider - Ingenio 2010 CSD2009-00065), and by the project "Natural and anthropogenic changes in Mediterranean river drainage basins: historical impacts on rivers morphology, sedimentary flows and vegetation” of the Spanish MINECO (CGL2013-44917R). Virginia Garófano-Gómez received a post-doctoral grant from the Université Blaise Pascal (now: Université Clermont Auvergne). Rui Rivaes benefited from a PhD grant (SFRH/BD/52515/2014) sponsored by Fundação para a Ciência e Tecnologia (FCT) under the FCT PhD program FLUVIO - 
River Restoration and Management. Patricia María Rodríguez González was funded by FCT through SFRH/BPD/47140/2008 postdoc fellowship and through FCT Investigator Programme grant (IF/00059/2015). The authors also thank all the colleagues and master students who contributed enthusiastically to the field campaigns of this study.

\section{REFERENCES}

Alcaraz-Hernández JD, Muñoz-Mas R, Martínez-Capel F, Garófano-Gómez V, Vezza P, 2016. Generalized additive models to predict adult and young brown trout (Salmo trutta Linnaeus, 1758) densities in Mediterranean rivers. Journal of Applied Ichthyology 32(1), 217-228. DOI: 10.1111/jai.13025.

Arlot S, Celisse A, 2010. A survey of cross-validation procedures for model selection. Statistics Surveys 4, 40-79. DOI: 10.1214/09-SS054.

Arthington AH, Bunn SE, Poff NL, Naiman RJ, 2006. The challenge of providing environmental flow rules to sustain river ecosystems. Ecological Applications 16(4), 1311-1318. DOI: 10.1890/1051-0761(2006)016[1311:TCOPEF]2.0.CO;2.

Auble G, Scott M, 1998. Fluvial disturbance patches and cottonwood recruitment along the upper Missouri River, Montana. Wetlands 18(4), 546-556. DOI: 10.1007/bf03161671.

Austin M, 2007. Species distribution models and ecological theory: A critical assessment and some possible new approaches. Ecological Modelling 200(1-2), 1-19. DOI: 10.1016/j.ecolmodel.2006.07.005.

Bagstad KJ, Lite SJ, Stromberg JC, 2006. Vegetation, soils, and hydrogeomorphology of riparian patch types of a dryland river. Western North American Naturalist 66(1), 23-44. DOI: 10.3398/1527-0904(2006)66[23:vsahor]2.0.co;2. 
Barletta M, Jaureguizar AJ, Baigun C, Fontoura NF, Agostinho AA, Almeida-Val VMF, Val AL, Torres RA, Jimenes-Segura LF, Giarrizzo T, Fabré NN, Batista VS, Lasso C, Taphorn DC, Costa MF, Chaves PT, Vieira JP, Corrêa MFM, 2010. Fish and aquatic habitat conservation in South America: A continental overview with emphasis on neotropical systems. Journal of Fish Biology 76(9), 2118-2176. DOI: 10.1111/j.1095-8649.2010.02684.x.

Barsoum N, 2001. Relative contributions of sexual and asexual regeneration strategies in Populus nigra and Salix alba during the first years of establishment on a braided gravel bed river. Evolutionary Ecology 15(4-6), 255-279. DOI: 10.1023/A:1016028730129.

Baxter C V., Fausch KD, Carl Saunders W, 2005. Tangled webs: reciprocal flows of invertebrate prey link streams and riparian zones. Freshwater Biology 50(2), 201-220. DOI: 10.1111/j.13652427.2004.01328.x.

Bejarano MD, González del Tánago M, de Jalón DG, Marchamalo M, Sordo-Ward Á, SolanaGutiérrez J, 2012a. Responses of riparian guilds to flow alterations in a Mediterranean stream. Journal of Vegetation Science 23(3), 443-458. DOI: 10.1111/j.1654-1103.2011.01360.x.

Bejarano MD, Marchamalo M, González del Tánago M, García de Jalón D, Sordo-Ward Á, 2012b. Riparian guild composition changes along a regulated Mediterranean stream in Central-Western Spain. In: Proceedings of the 9th International Symposium on Ecohydraulics, Mader H, Kraml J (Eds.). Published by ISE 2012 Organizing Committee: Vienna (Austria).

Bejarano MD, Nilsson C, González del Tánago M, Marchamalo M, 2011. Responses of riparian trees and shrubs to flow regulation along a boreal stream in northern Sweden. Freshwater Biology 56(5), 853-866. DOI: 10.1111/j.1365-2427.2010.02531.x.

Benjankar R, Burke M, Yager E, Tonina D, Egger G, Rood SB, Merz N, 2014. Development of a spatially-distributed hydroecological model to simulate cottonwood seedling recruitment along rivers. Journal of environmental management 145, 277-88. DOI: 
10.1016/j.jenvman.2014.06.027.

Benjankar R, Egger G, Jorde K, Goodwin P, Glenn NF, 2011. Dynamic floodplain vegetation model development for the Kootenai River, USA. Journal of Environmental Management 92(12), 3058-3070. DOI: 10.1016/j.jenvman.2011.07.017.

Bertoldi W, Siviglia A, Tettamanti S, Toffolon M, Vetsch D, Francalanci S, 2014. Modeling vegetation controls on fluvial morphological trajectories. Geophysical Research Letters 41(20), 7167-7175. DOI: 10.1002/2014GL061666.

Blackard JA, Dean DJ, 1999. Comparative accuracies of artificial neural networks and discriminant analysis in predicting forest cover types from cartographic variables. Computers and Electronics in Agriculture 24(3), 131-151. DOI: 10.1016/S0168-1699(99)00046-0.

Boavida I, Santos JM, Pinheiro AN, Ferreira MT, 2011. Fish habitat availability simulations using different morphological variables. Limnetica 30(2), 393-404.

Camporeale C, Perucca E, Ridolfi L, Gurnell AM, 2013. Modeling the interactions between river morphodynamics and riparian vegetation. Reviews of Geophysics 51(3), 379-414. DOI: 10.1002/rog.20014.

Carbonneau P, Fonstad MAMA, Marcus WAA, Dugdale SJSJ, 2012. Making riverscapes real. Geomorphology 137(1), 74-86. DOI: 10.1016/j.geomorph.2010.09.030.

Cerone A, Scotti M, 2015. Research Challenges in Modelling Ecosystems. In: Software Engineering and Formal Methods, Canal C, Idani A (Eds.). Springer International Publishing; 276-293.

Corenblit D, Steiger J, Gurnell AM, Tabacchi E, Roques L, 2009. Control of sediment dynamics by vegetation as a key function driving biogeomorphic succession within fluvial corridors. Earth Surface Processes and Landforms 34(13), 1790-1810. DOI: 10.1002/esp.1876.

Corenblit D, Tabacchi E, Steiger J, Gurnell AM, 2007. Reciprocal interactions and adjustments 
between fluvial landforms and vegetation dynamics in river corridors: A review of complementary approaches. Earth-Science Reviews 84(1-2), 56-86. DOI: 10.1016/j.earscirev.2007.05.004.

Corenblit D, Vidal V, Cabanis M, Steiger J, Garófano-Gómez V, Garreau A, Hortobágyi B, Otto T, Roussel E, Voldoire O, 2016. Seed retention by pioneer trees enhances plant diversity resilience on gravel bars: Observations from the river Allier, France. Advances in Water Resources 93, 182-192. DOI: 10.1016/j.advwatres.2016.02.015.

Costa RMS, Martínez-Capel F, Muñoz-Mas R, Alcaraz-Hernández JD, Garófano-Gómez V, 2012. Habitat suitability modelling at mesohabitat scale and effects of dam operation on the endangered Júcar nase, Parachondrostoma arrigonis (River Cabriel, Spain). River Research and Applications 28(6), 740-752. DOI: http://dx.doi.org/10.1002/rra.1598.

Coulthard TJ, Hicks DM, Van De Wiel MJ, 2007. Cellular modelling of river catchments and reaches: Advantages, limitations and prospects. Geomorphology 90(3), 192-207. DOI: 10.1016/j.geomorph.2006.10.030.

Cox DR, 1958. The Regression Analysis of Binary Sequences. Journal of the Royal Statistical Society. Series B (Methodological) 20(2), 215-242.

Darby SE, Simon A, 1999. Incised river channels: processes, forms, engineering, and management. J. Wiley: Chichester, (UK).

De Jager NR, Thomsen M, Yin Y, 2012. Threshold effects of flood duration on the vegetation and soils of the Upper Mississippi River floodplain, USA. Forest Ecology and Management 270, 135-146. DOI: 10.1016/j.foreco.2012.01.023.

Egger G, Politti E, Garófano-Gómez V, Blamauer B, Ferreira MT, Rivaes R, Benjankar R, Habersack H, 2013. Embodying interactions of riparian vegetation and fluvial processes into a dynamic floodplain model: concepts and applications. In: Ecohydraulics: An Integrated 
Approach, Maddock I, Harby A, Kemp P, Wood P (Eds.). John Wiley \& Sons Ltd: Chichester, (UK); 407-427.

Egger G, Politti E, Lautsch E, Benjankar R, Gill KM, Rood SB, 2015. Floodplain forest succession reveals fluvial processes: A hydrogeomorphic model for temperate riparian woodlands. Journal of environmental management 161, 72-82. DOI: 10.1016/j.jenvman.2015.06.018.

Egger G, Politti E, Lautsch E, Benjankar RM, Rood SB, 2017. Time and Intensity Weighted Indices of Fluvial Processes: a Case Study from the Kootenai River, USA. River Research and Applications 33(2), 224-232. DOI: 10.1002/rra.2997.

Egger G, Politti E, Woo H, Cho KH, Park M, Cho H, Benjankar R, Lee NJ, Lee H, 2012. Dynamic vegetation model as a tool for ecological impact assessments of dam operation. Journal of Hydro-environment Research 6(2), 151-161. DOI: 10.1016/j.jher.2012.01.007.

Fausch KD, Torgersen CE, Baxter C V, Li HW, 2002. Landscapes to riverscapes: Bridging the gap between research and conservation of stream fishes. BioScience 52(6), 483-498.

Formann E, Habersack HM, Schober S, 2007. Morphodynamic river processes and techniques for assessment of channel evolution in Alpine gravel bed rivers. Geomorphology 90(3-4), 340-355. DOI: 10.1016/j.geomorph.2006.10.029.

Fox J, 2010. polycor: Polychoric and Polyserial Correlations.

Fraaije RGA, ter Braak CJF, Verduyn B, Breeman LBS, Verhoeven JTA, Soons MB, 2015. Early plant recruitment stages set the template for the development of vegetation patterns along a hydrological gradient. Functional Ecology 29(7), 971-980. DOI: 10.1111/1365-2435.12441.

Francés F, Real J, García-Arias A, Andrés-Doménech I, Vallés-Morán F, Martínez-Capel F, Garófano-Gómez V, Ferreira MT, Rodríguez-González PM, Rivaes R, Pinheiro A, Egger G, Angermann K, Politti E, 2011. Ripflow Project. Final report. Riparian vegetation modelling for 
the assessment of environmental flow regimes and climate change impacts within the WFD. València (Spain).

Friedman JH, 2001. Greedy function approximation: A gradient boosting machine. Annals of Statistics 29(5), 1189-1232. DOI: 10.1214/aos/1013203451.

Fritts HC, 1972. Tree Rings and Climate. Scientific American 226(5), 92-100. DOI: 10.1038/scientificamerican0572-92.

Fukuda S, De Baets B, Waegeman W, Verwaeren J, Mouton AM, 2013. Habitat prediction and knowledge extraction for spawning European grayling (Thymallus thymallus L.) using a broad range of species distribution models. Environmental Modelling \& Software 47, 1-6. DOI: 10.1016/j.envsoft.2013.04.005.

Gabriel KR, 1971. The biplot graphic display of matrices with application to principal component analysis. Biometrika 58(3), 453-467. DOI: 10.1093/biomet/58.3.453.

García-Arias A, Francés F, 2016. The RVDM: modelling impacts, evolution and competition processes to determine riparian vegetation dynamics. Ecohydrology 9(3), 438-459. DOI: 10.1002/eco.1648.

García-Arias A, Francés F, Ferreira T, Egger G, Martínez-Capel F, Garófano-Gómez V, AndrésDoménech I, Politti E, Rivaes R, Rodríguez-González PM, 2013. Implementing a dynamic riparian vegetation model in three European river systems. Ecohydrology 6(4), 635-651. DOI: 10.1002/eco.1331.

Garófano-Gómez V, Martínez-Capel F, Bertoldi W, Gurnell A, Estornell J, Segura-Beltrán F, 2013. Six decades of changes in the riparian corridor of a Mediterranean river: a synthetic analysis based on historical data sources. Ecohydrology 6(4), 536-553. DOI: 10.1002/eco.1330.

Garófano-Gómez V, Martínez-Capel F, Francés F, 2009. Distribution patterns of riparian species in 
relation to channel bed in two Mediterranean rivers. In: Proc. 7th International Symposium on Ecohydraulics, Int. Association of Hydraulic Engineering and Research (IAHR) - University of Concepción (Chile) (Ed.). ISE 2009 Organizing Committee: Concepción (Chile); 12-16.

Geerling GW, Ragas AMJ, Leuven RSEW, van den Berg JH, Breedveld M, Liefhebber D, Smits AJM, 2006. Succession and Rejuvenation in Floodplains along the River Allier (France). Hydrobiologia 565(1), 71-86. DOI: 10.1007/s10750-005-1906-6.

Glenz C, Iorgulescu I, Kienast F, Schlaepfer R, 2008. Modelling the impact of flooding stress on the growth performance of woody species using fuzzy logic. Ecological Modelling 218(1-2), 1828. DOI: 10.1016/j.ecolmodel.2008.06.008.

González E, González-Sanchis M, Comín FA, Muller E, 2012. Hydrologic thresholds for riparian forest conservation in a regulated large Mediterranean river. River Research and Applications 28(1), 71-80. DOI: 10.1002/rra.1436.

Gran KB, Tal M, Wartman ED, 2015. Co-evolution of riparian vegetation and channel dynamics in an aggrading braided river system, Mount Pinatubo, Philippines. Earth Surface Processes and Landforms 40(8), 1101-1115. DOI: 10.1002/esp.3699.

Grossman D, Faber-Langendoen D, Weakley A, Anderson A, Bourgeron P, Crawford R, Goodin K, Landaal S, Metzler K, Patterson K, Pyne M, Reid M, Sneddon L, 2001. Terrestrial vegetation of the United States. Choice Reviews Online.

Gurnell A, 2014. Plants as river system engineers. Earth Surface Processes and Landforms 39(1), 4 25. DOI: $10.1002 /$ esp.3397.

Gurnell AM, Corenblit D, García de Jalón D, González del Tánago M, Grabowski RC, O’Hare MT, Szewczyk M, 2016. A Conceptual Model of Vegetation-hydrogeomorphology Interactions Within River Corridors. River Research and Applications 32(2), 142-163. DOI: 10.1002/rra.2928. 
Habersack H, Haspel D, Kondolf M, 2014. Large Rivers in the Anthropocene: Insights and tools for understanding climatic, land use, and reservoir influences. Water Resources Research 50(5), 3641-3646. DOI: 10.1002/2013WR014731.

Hastie TJ, Tibshirani RJ, 1990. Generalized Additive Models. Monographs on Statistics \& Applied Probability. Chapman \& Hall/CRC: London, (UK).

Hiemstra PH, Pebesma EJ, Twenhöfel CJW, Heuvelink GBM, 2009. Real-time automatic interpolation of ambient gamma dose rates from the Dutch radioactivity monitoring network. Computers \& Geosciences 35(8), 1711-1721. DOI: 10.1016/j.cageo.2008.10.011.

Holland JH, 1992. Genetic algorithms. Scientific American 267(1), 66-72.

Hough-Snee N, Laub BG, Merritt DM, Long AL, Nackley LL, Roper BB, Wheaton JM, 2015. Multiscale environmental filters and niche partitioning govern the distributions of riparian vegetation guilds. Ecosphere 6(10), art173. DOI: 10.1890/ES15-00064.1.

Hurlbert SH, 1984. Pseudoreplication and the Design of Ecological Field Experiments. Ecological Monographs 54(2), 187-211. DOI: 10.2307/1942661.

Jones CG, Lawton JH, Shachak M, 1994. Organisms as Ecosystem Engineers. In: Ecosystem Management, . Springer New York: New York, NY; 130-147.

Jones EBD, Helfman GS, Harper JO, Bolstad P V., 1999. Effects of Riparian Forest Removal on Fish Assemblages in Southern Appalachian Streams. Conservation Biology 13(6), 1454-1465. DOI: 10.1046/j.1523-1739.1999.98172.x.

Karrenberg S, Edwards PJJ, Kollmann J, 2002. The life history of Salicaceae living in the active zone of floodplains. Freshwater Biology 47(4), 733-748. DOI: 10.1046/j.13652427.2002.00894.x.

Karthe D, Chalov S, Borchardt D, 2014. Water resources and their management in central Asia in the 
early twenty first century: status, challenges and future prospects. Environmental Earth Sciences 73(2), 487-499. DOI: 10.1007/s12665-014-3789-1.

Korup O, 2005. Geomorphic imprint of landslides on alpine river systems, southwest New Zealand. Earth Surface Processes and Landforms 30(7), 783-800. DOI: 10.1002/esp.1171.

Kovalchik BL, Clausnitzer RR, 2004. Classification and management of aquatic, riparian, and wetland sites on the National Forests of Eastern Washington: Series description. Portland, OR (USA).

Lecerf A, Dobson M, Dang CK, Chauvet E, 2005. Riparian plant species loss alters trophic dynamics in detritus-based stream ecosystems. Oecologia 146(3), 432-442. DOI: 10.1007/s00442-0050212-3.

Looy K Van, Honnay O, Pedroli B, Muller S, 2006. Order and disorder in the river continuum: The contribution of continuity and connectivity to floodplain meadow biodiversity. Journal of Biogeography 33(9), 1615-1627. DOI: 10.1111/j.1365-2699.2006.01536.x.

Méndez-Toribio M, Zermeño-Hernández I, Ibarra-Manríquez G, 2014. Effect of land use on the structure and diversity of riparian vegetation in the Duero river watershed in Michoacán, Mexico. Plant Ecology 215(3), 285-296. DOI: 10.1007/s11258-014-0297-z.

Merritt DM, Scott ML, LeRoy Poff N, Auble GT, Lytle DA, 2010. Theory, methods and tools for determining environmental flows for riparian vegetation: riparian vegetation-flow response guilds. Freshwater Biology 55(1), 206-225. DOI: 10.1111/j.1365-2427.2009.02206.x.

Meybeck M, 2004. The global change of continental aquatic systems: Dominant impacts of human activities. Water Science and Technology 49(7), 73-83.

Moret SL, Langford WT, Margineantu DD, 2006. Learning to predict channel stability using biogeomorphic features. Ecological Modelling 191(1), 47-57. DOI: 
10.1016/j.ecolmodel.2005.08.011.

Morse NB, Pellissier PA, Cianciola EN, Brereton RL, Sullivan MM, Shonka NK, Wheeler TB, McDowell WH, 2014. Novel ecosystems in the Anthropocene: a revision of the novel ecosystem concept for pragmatic applications. Ecology and Society 19(2), art12. DOI: 10.5751/ES-06192-190212.

Mouton AM, Alcaraz-Hernández JD, De Baets B, Goethals PLM, Martínez-Capel F, 2011. Datadriven fuzzy habitat suitability models for brown trout in Spanish Mediterranean rivers. Environmental Modelling \& Software 26(5), 615-622. DOI: 10.1016/j.envsoft.2010.12.001.

Mouton AM, De Baets B, Goethals PLM, 2010. Ecological relevance of performance criteria for species distribution models. Ecological Modelling 221(16), 1995-2002. DOI: 10.1016/j.ecolmodel.2010.04.017.

Mouw JEB, Chaffin JL, Whited DC, Hauer FR, Matson PL, Stanford JA, 2013. Recruitment and successional dynamics diversify the shifting habitat mosaic of an Alaskan floodplain. River Research and Applications 29(6), 671-685. DOI: 10.1002/rra.2569.

Mullen KM, Ardia D, Gil DL, Windover D, Cline J, 2011. DEoptim: An R package for global optimization by differential evolution. Journal of Statistical Software 40(6), 1-26.

Muñoz-Mas R, Fukuda S, Vezza P, Martínez-Capel F, 2016. Comparing four methods for decisiontree induction: A case study on the invasive Iberian gudgeon (Gobio lozanoi; Doadrio and Madeira, 2004). Ecological Informatics 34, 22-34. DOI: 10.1016/j.ecoinf.2016.04.011.

Muñoz-Mas R, Lopez-Nicolas A, Martínez-Capel F, Pulido-Velazquez M, 2016a. Shifts in the suitable habitat available for brown trout (Salmo trutta L.) under short-term climate change scenarios. Science of The Total Environment 544, 686-700. DOI: 10.1016/j.scitotenv.2015.11.147. 
Muñoz-Mas R, Martínez-Capel F, Alcaraz-Hernández JD, Mouton AM, 2015. Can multilayer perceptron ensembles model the ecological niche of freshwater fish species? Ecological Modelling 309-310(0), 72-81. DOI: http://dx.doi.org/10.1016/j.ecolmodel.2015.04.025.

Muñoz-Mas R, Papadaki C, Martínez-Capel F, Zogaris S, Ntoanidis L, Dimitriou E, $2016 b$. Generalized additive and fuzzy models in environmental flow assessment: A comparison employing the West Balkan trout (Salmo farioides; Karaman, 1938). Ecological Engineering 91, 365-377. DOI: 10.1016/j.ecoleng.2016.03.009.

Murillo J, Rodríguez Pallarés M, Andrés-Urrutia A, Brufau P, García-Navarro P, 2008. A mathematical model for numerical simulation of shallow water flow: Description and practical application of GUAD|2D. In: 4th Biennial Meeting of International Congress on Environmental Modelling and Software: Integrating Sciences and Information Technology for Environmental Assessment and Decision Making, iEMSs 2008, . 1431-1438.

Murray AB, Paola C, 2003. Modelling the effect of vegetation on channel pattern in bedload rivers. Earth Surface Processes and Landforms 28(2), 131-143. DOI: 10.1002/esp.428.

Naiman RJ, Décamps H (Henri), McClain ME, 2005. Riparia: ecology, conservation, and management of streamside communities. Elsevier Academic.

Naiman RJ, Latterell JJ, Pettit NE, Olden JD, 2008. Flow variability and the biophysical vitality of river systems. Comptes Rendus Geoscience 340(9), 629-643. DOI: 10.1016/j.crte.2008.01.002.

Nelder JA, Wedderburn RWM, 1972. Generalized Linear Models. Journal of the Royal Statistical Society. Series A (General) 135(3), 370-384. DOI: 10.2307/2344614.

Nilsson C, Reidy CA, Dynesius M, Revenga C, 2005. Fragmentation and flow regulation of the world’s large river systems. Science 308(5720), 405-8. DOI: 10.1126/science.1107887.

Oliver CD, Larson BC, 1996. Forest Stand Dynamics. Updated edition. John Wiley \& Sons, Inc. 
Paliy O, Shankar V, 2016. Application of multivariate statistical techniques in microbial ecology. Molecular Ecology 25(5), 1032-1057. DOI: 10.1111/mec.13536.

Paz-Kagan T, Zaady E, Shachak M, Karnieli A, 2016. Transformation of shrublands to forests: The role of woody species as ecosystem engineers and landscape modulators. Forest Ecology and Management 361, 257-268. DOI: 10.1016/j.foreco.2015.11.021.

Pearson K, 1901. On lines and planes of closest fit to systems of points in space. Philosophical Magazine Series 6 2(11), 559-572. DOI: 10.1080/14786440109462720.

Peel MC, Finlayson BL, McMahon TA, 2007. Updated world map of the Köppen-Geiger climate classification. Hydrology and Earth System Sciences 11(5), 1633-1644. DOI: 10.5194/hess-111633-2007.

Peters J, Verhoest NEC, Samson R, Boeckx P, De Baets B, 2008. Wetland vegetation distribution modelling for the identification of constraining environmental variables. Landscape Ecology 23(9), 1049-1065. DOI: 10.1007/s10980-008-9261-4.

Petts GE, Gurnell AM, 2005. Dams and geomorphology: Research progress and future directions. Geomorphology 71(1), 27-47. DOI: 10.1016/j.geomorph.2004.02.015.

Pickett STA, White PS, 1985. Patch dynamics: a synthesis. In: The Ecology of Natural Disturbance and Patch Dynamics, Pickett STA, White PS (Eds.). Academic Press: Orlando, Florida (USA); $371-384$.

Platts PJ, McClean CJ, Lovett JC, Marchant R, 2008. Predicting tree distributions in an East African biodiversity hotspot: model selection, data bias and envelope uncertainty. Ecological Modelling 218(1-2), 121-134. DOI: 10.1016/j.ecolmodel.2008.06.028.

Poff NL, Allan JD, Bain MB, Karr JR, Prestegaard KL, Richter BD, Sparks RE, Stromberg JC, 1997. The natural flow regime: A paradigm for river conservation and restoration. BioScience 47(11), 
769-784. DOI: 10.2307/1313099.

Politti E, Egger G, Angermann K, Rivaes R, Blamauer B, Klösch M, Tritthart M, Habersack H, 2014. Evaluating climate change impacts on Alpine floodplain vegetation. Hydrobiologia 737(1), 225-243. DOI: 10.1007/s10750-013-1801-5.

Quinn GP, Keough MJ, 2002. Experimental Design and Data Analysis for Biologists. Cambridge University Press: Cambridge, (UK).

R Core Team, 2015. R: A language and environment for statistical computing.

Revelle W, 2015. Package “psych” - Procedures for Psychological, Psychometric and Personality Research.

Rivaes R, Rodríguez-González PM, Albuquerque A, Pinheiro AN, Egger G, Ferreira MT, 2013. Riparian vegetation responses to altered flow regimes driven by climate change in Mediterranean rivers. Ecohydrology 6(3), 413-424. DOI: 10.1002/eco.1287.

Rivaes RP, Rodríguez-González PM, Ferreira MT, Pinheiro AN, Politti E, Egger G, García-Arias A, Francés F, 2014. Modeling the evolution of riparian woodlands facing climate change in three european rivers with contrasting flow regimes. PLOS ONE 9(10), e110200. DOI: 10.1371/journal.pone.0110200.

Shoutis L, Patten DT, McGlynn B, 2010. Terrain-based Predictive Modeling of Riparian Vegetation in a Northern Rocky Mountain Watershed. Wetlands 30(3), 621-633. DOI: 10.1007/s13157010-0047-5.

Solari L, Van Oorschot M, Belletti B, Hendriks D, Rinaldi M, Vargas-Luna A, 2016. Advances on Modelling Riparian Vegetation-Hydromorphology Interactions. River Research and Applications 32(2), 164-178. DOI: 10.1002/rra.2910.

Steffler P, Blackburn J, 2002. River2D. 
Stella JC, Rodríguez-González PM, Dufour S, Bendix J, 2012. Riparian vegetation research in Mediterranean-climate regions: common patterns, ecological processes, and considerations for management. Hydrobiologia 719(1), 291-315. DOI: 10.1007/s10750-012-1304-9.

Storn R, Price K, 1997. Differential Evolution - A Simple and Efficient Heuristic for global Optimization over Continuous Spaces. Journal of Global Optimization 11(4), 341-359. DOI: 10.1023/A:1008202821328.

Ström L, Jansson R, Nilsson C, 2012. Projected changes in plant species richness and extent of riparian vegetation belts as a result of climate-driven hydrological change along the Vindel River in Sweden. Freshwater Biology 57(1), 49-60. DOI: 10.1111/j.1365-2427.2011.02694.x.

Stromberg J, 1998. Dynamics of Fremont cottonwood (Populus fremontii) and saltcedar (Tamarix chinensis) populations along the San Pedro River, Arizona. Journal of Arid Environments 40(2), 133-155.

Stromberg JC, Merritt DM, 2016. Riparian plant guilds of ephemeral, intermittent and perennial rivers. Freshwater Biology 61(8), 1259-1275. DOI: 10.1111/fwb.12686.

Tritthart M, Gutknecht D, 2007. Three-Dimensional Simulation of Free-Surface Flows using Polyhedral Finite Volumes. Engineering Applications of Computational Fluid Mechanics 1(1), 1-14. DOI: 10.1080/19942060.2007.11015177.

Turner MG, Gergel SE, Dixon MD, Miller JR, 2004. Distribution and abundance of trees in floodplain forests of the Wisconsin River: Environmental influences at different scales. Journal of Vegetation Science 15(6), 729-738. DOI: 10.1111/j.1654-1103.2004.tb02315.x.

van Oorschot M, Kleinhans M, Geerling G, Middelkoop H, 2016. Distinct patterns of interaction between vegetation and morphodynamics. Earth Surface Processes and Landforms 41(6). DOI: 10.1002/esp.3864. 
Vannote RL, Minshall GW, Cummins KW, Sedell JR, Cushing CE, 1980. The River Continuum Concept. Canadian Journal of Fisheries and Aquatic Sciences 37(1), 130-137.

Violle C, Navas M-L, Vile D, Kazakou E, Fortunel C, Hummel I, Garnier E, 2007. Let the concept of trait be functional! Oikos 116(5), 882-892. DOI: 10.1111/j.0030-1299.2007.15559.x.

Wood SN, 2004. Stable and efficient multiple smoothing parameter estimation for generalized additive models. Journal of the American Statistical Association 99(467), 673-686. DOI: 10.1198/016214504000000980.

Wootton JT, Parker MS, Power ME, 1996. Effects of Disturbance on River Food Webs. Science 273(5281), 1558-1561. DOI: 10.1126/science.273.5281.1558.

Ye F, Chen Q, Blanckaert K, Ma J, 2013. Riparian vegetation dynamics: insight provided by a process-based model, a statistical model and field data. Ecohydrology 6(4), 567-585. DOI: 10.1002/eco.1348.

Zadeh LA, 1965. Fuzzy sets. Information and Control 8(3), 338-353. DOI: 10.1016/S00199958(65)90241-X.

Zuur AF, Ieno EN, Smith GM, 2007. Analysing Ecological Data. Statistics for Biology and Health. Springer New York: New York (NY). 
Table 1. Scores, labels, timeframes and description of the categories employed for the variables geomorphic disturbance and flood frequency (modified from Egger et al., 2015).

\begin{tabular}{|c|c|c|c|c|}
\hline \multirow{2}{*}{ Score } & \multirow{2}{*}{ Label } & \multirow{2}{*}{ Timeframe } & \multicolumn{2}{|c|}{ Description } \\
\hline & & & Geomorphic disturbance & Flood frequency \\
\hline 2 & High & $1 \leq \#$ years $<3$ & $\begin{array}{l}\text { Annual moderate erosion and sedimentation, sand } \\
\text { or gravel with no organic horizon and a thin litter } \\
\text { layer, pioneer vegetation with reeds and flow- } \\
\text { resistant woody plants, often with damage including } \\
\text { sheared branches and braided trunks }\end{array}$ & $\begin{array}{l}\text { Flooded once or a few times annually by discharges } \\
\text { from } \mathrm{Q}_{1} \text { (i.e., first quantile) to bank-full flow, some } \\
\text { flooding indicators and flood-tolerant plant species }\end{array}$ \\
\hline 3 & Moderate & $3 \leq \#$ years $<10$ & $\begin{array}{l}\text { Morphodynamic processes generally limited to } \\
\text { slight sedimentation of sand and local erosion; } \\
\text { weak organic layer and distinct litter layer; dense } \\
\text { reed or intermediate flow-resistant woody plants }\end{array}$ & $\begin{array}{l}\text { Stage ranges from bank-full to medium floods, } \\
\text { flooding indicators only after major floods; some } \\
\text { moderately flood-sensitive species, mostly perennials, } \\
\text { trees and shrubs }\end{array}$ \\
\hline 4 & Low & $10 \leq \#$ years $<30$ & $\begin{array}{l}\text { Low level of morphodynamic processes with weak } \\
\text { intensity, limited local erosion and sedimentation of } \\
\text { fine sand and silt; distinct organic and litter layer; } \\
\text { young or intermediate deciduous forest }\end{array}$ & $\begin{array}{l}\text { Only inundated with moderate to major floods, } \\
\text { flooding plays a minor role, low effect on tree layer, } \\
\text { understory with mature indicator species }\end{array}$ \\
\hline
\end{tabular}


Table 2. Description of the succession phases of the riparian woodland series.

Stage Woodland phases

Initial phase

Colonization

stage

Pioneer phase

Herb phase

Pioneer shrub

phase

Transitional Shrub phase

stage

Early

successional

phase

Established forest phase

Mature stage
Mature forest

phase
Description

Open bare sediment (e.g. gravel and sand) with a total vegetation ground cover < 25\% (Grossman et al., 2001), absent of potential woody arboreal species. Seedlings only become established for a short time period due to the high frequency of disturbance. Groundwater is typically near the surface.

Moist mineral soil and free of competing established vegetation and plant litter (Auble and Scott, 1998) where initial seedling establishment occurs, mainly of ruderal, stress-tolerant and disturbance-adapted pioneer species (e.g., Salicaceae and

Tamaricaceae) with an effective generative multiplication as well as the ability to vegetative propagation (Karrenberg et al., 2002). Large pieces of wood deposited during the initial phase allow the rapid re-establishment of vegetative biomass in the early stages of post-flood riparian forest renewal (Naiman et al., 2008), as they are able to trap seeds and fine sediment (Corenblit et al., 2016). Biomass production, standing biomass and age of vegetation is low, whereas species diversity is high with a low vegetation ground cover ( 35\%).

Patches mainly composed by annual and biannual short-lived herbaceous species with a ruderal or competitive strategy able to colonize spaces immediately after disturbance events, as they grow rapidly and complete their life cycles before other plants are able to replace them (Oliver and Larson, 1996). It may comprise scattered woody pioneer individuals.

Intermediate between pioneer and shrub phase. Pioneer woody plants withstand relatively low energy floods and are still a passive hydraulic element.

Woody and long-lived species with stress-tolerant and competitive development strategies. It is particularly dominated by microphanerophytes species. Shrub-like is the dominant life form in the patch. The dimensions of the aerial structures allow the plants to interact with the flow field and locally modify flow velocity and depth, thus actively contributing to geomorphic processes. Root systems are well developed and provide strong anchorage that during floods bound the plants to the ground unless consistent erosion occurs.

Stem exclusion phase (sensu Naiman et al., 2005). Macrophanerophytes start to compose the understory vegetation and certain fast growing pioneer species start changing from a multi-stemmed to a single-stemmed habit (e.g., Populus spp.). Standing biomass is moderate (open soil < 35\%). Plant community is more persistent, complex and diverse.

Understory re-initiation phase (sensu Naiman et al., 2005; Oliver and Larson, 1996) where the canopy cover is high (open soil < $20 \%$ ) and multi-layered. The habitat is less prone to disturbance and an A-horizon is present. Macrophanerophytes like poplar or ash-tree usually dominate the tree layer. However, the riparian understory composition starts shifting toward shade-tolerant, slowgrowing species more adapted to drier and stable habitat conditions (Bagstad et al., 2006), such as Ulmus, Quercus or Picea spp. Patches include a mixed-forest composed by a combination of woody and long-lived riparian and terrestrial arboreal species. The standing biomass and species diversity are high. Individual overstory trees may die as the forest stand ages, opening up canopy space which leads rapidly to regeneration of the understory stands. Trees regenerate and grow without the influence of external disturbances. Living old trees and dead standing trees occur together with a diverse understory and several layers of vegetation. 
Table 3. Differential Evolution (DEoptim) and Genetic Algorithm (genoud) parameters settings.

$$
\text { DEoptim Genoud }
$$

\begin{tabular}{lclc}
\multicolumn{1}{c}{ Operator } & Setting & \multicolumn{1}{c}{ Operator } & Setting \\
\hline Value to be reached & 0 & Cloning & 0.25 \\
Strategy & 2 & Uniform mutation & 0.75 \\
Population size & 100 & Boundary mutation & 0 \\
Maximum iterations allowed & 500 & Non-uniform mutation & 0 \\
Crossover adaptation & 0.5 & Polytope crossover & 0 \\
Relative convergence tolerance & 0.001 & Simple crossover & 0.75 \\
Step tolerance & 20 & Whole non-uniform mutation & 0 \\
Crossover probability & 0.5 & Heuristic crossover & 0 \\
Store population from & 1 & Local-minimum crossover & 0 \\
\hline
\end{tabular}


Table 4. Total number of independent patches (N), data prevalence and number of pixels (between brackets) for each of the succession woodland phases and folds employed in each site during the Cross-Validation (CV).

\begin{tabular}{|c|c|c|c|c|c|c|c|c|c|c|c|c|}
\hline \multirow[b]{2}{*}{ Woodland phases } & \multicolumn{4}{|c|}{ Austria } & \multicolumn{4}{|c|}{ Portugal } & \multicolumn{4}{|c|}{ Spain } \\
\hline & $\mathrm{N}$ & Fold 1 & Fold 2 & Fold 3 & $\mathrm{~N}$ & Fold 1 & Fold 2 & Fold 3 & $\mathrm{~N}$ & Fold 1 & Fold 2 & Fold 3 \\
\hline Pioneer phase & 13 & $0.12(533)$ & $0.13(579)$ & $0.00(15)$ & 12 & $0.03(163)$ & $0.03(161)$ & $0.02(128)$ & 2 & $0.00(29)$ & $0.00(13)$ & $0.00(13)$ \\
\hline Pioneer shrub phase & 5 & $0.09(372)$ & $0.09(371)$ & $0.07(296)$ & & & & & & & & \\
\hline Shrub phase & 2 & $0.02(88)$ & $0.02(100)$ & 0.03 (113) & & & & & 18 & $0.06(615)$ & $0.05(554)$ & $0.07(756)$ \\
\hline Early successional phase & & & & & 32 & $0.10(594)$ & $0.06(382)$ & $0.09(542)$ & 11 & 0.03 (339) & 0.07 (808) & 0.13 (1439) \\
\hline
\end{tabular}


Table 5. Performance criteria - True Skill Statistic ( $\overline{\mathrm{TSS}})$, Sensitivity $(\overline{\mathrm{Sn}})$ and Specificity $(\overline{\mathrm{Sp}})$ obtained during the optimization of the GAMs. The table depicts mean values obtained during the 3fold Cross-Validation (CV).

\begin{tabular}{|c|c|c|c|c|c|c|c|c|c|c|}
\hline \multirow{2}{*}{ Stage } & \multirow{2}{*}{ Woodland phases } & \multicolumn{3}{|c|}{ Austria } & \multicolumn{3}{|c|}{ Portugal } & \multicolumn{3}{|c|}{ Spain } \\
\hline & & $\overline{T S S}$ & $\overline{\boldsymbol{S n}}$ & $\overline{S p}$ & $\overline{T S S}$ & $\overline{\boldsymbol{S n}}$ & $\overline{S p}$ & $\overline{T S S}$ & $\overline{S n}$ & $\overline{S p}$ \\
\hline \multirow{2}{*}{ Colonization stage } & Initial phase & 0.67 & 0.80 & 0.87 & 0.52 & 0.90 & 0.63 & 0.51 & 0.91 & 0.60 \\
\hline & Pioneer phase & 0.83 & 0.94 & 0.89 & 0.72 & 0.93 & 0.79 & 0.76 & 0.85 & 0.91 \\
\hline \multirow{5}{*}{ Transitional stage } & Herb phase & & & & & & & 0.53 & 0.78 & 0.75 \\
\hline & Pioneer shrub phase & 0.56 & 0.68 & 0.89 & & & & & & \\
\hline & Shrub phase & 0.48 & 0.63 & 0.85 & & & & 0.21 & 0.79 & 0.42 \\
\hline & Early successional phase & & & & 0.37 & 0.98 & 0.39 & 0.36 & 0.83 & 0.53 \\
\hline & Established forest & & & & 0.83 & 0.93 & 0.91 & 0.59 & 0.81 & 0.77 \\
\hline Mature stage & Mature forest & & & & 0.56 & 0.60 & 0.96 & 0.52 & 0.65 & 0.88 \\
\hline
\end{tabular}

